\title{
Mortality in Critically III Patients Does Not Differ according to Transfusion Strategy
}

\author{
Filippo Sanfilippo Luigi La Via Paolo Murabito Marinella Astuto \\ Department of Anaesthesia and Intensive Care, A.O.U. Policlinico-San Marco, Catania, Italy
}

Dear Editor,

We read with great interest the meta-analysis by Zhang et al. [1] comparing the effects of two transfusion strategies in critically ill patients. The authors conclude that the restrictive transfusion strategy potentially reduced in-hospital mortality in critically ill adults as compared with a more liberal strategy. Unfortunately, we have several concerns in regard to this study and its results. First of all, as per the inclusion criteria stated by the authors, the meta-analysis focused on trials reporting mortality in critically ill adults receiving restrictive or liberal red-cell transfusion. The authors decided to include only critically ill patients with hemoglobin concentrations of $90 \mathrm{~g} / \mathrm{L}$ or less on admission. Considering such criteria, we note that they missed the study by Mazza et al. [2] conducted in septic shock patients; conversely, they included the study by Mazer et al. [3] where the authors included patients with baseline values of hemoglobin over $130 \mathrm{~g} / \mathrm{L}$. Nonetheless, mild errors in inclusion of studies may happen [4], and our colleagues did a very hard work when screening studies from a huge literature search. Importantly, by strictly limiting the inclusion of studies according to the hemoglobin levels on admission, at least five important trials conducted in a cardiac surgery population [5-7] and in patients with traumatic brain injury $[8,9]$ were excluded by the meta-analysis. A second consideration that warrants further caution when interpreting the results of the meta-analysis [1] is the authors' choice to perform a meta-analysis with a fixed- effects model, which assumes that the "true effect" is the same across studies. However, it is unlikely that all included studies have an identical or similar "true effect" due to the clinical heterogeneity of the included populations, ranging from all the critically ill patients admitted to intensive care to a more specific population (septic shock or patients undergoing cardiac surgery). More importantly, the fixed-effects model should not be used when there is statistical heterogeneity $\left(I^{2}\right)$ as in most of the forest plots of the meta-analysis by Zhang et al. [1]. In such cases, it is strongly advisable to use a randomeffects model, which better balances the weights of the included studies [10].

A third concern regards the authors' decision to separate the analyses on the outcome of mortality into several endpoints. This resulted in 7 forest plots on the same outcome (mortality), but most of them included a very low number of studies (1-3 studies). For instance, the conclusion on a reduction of in-hospital mortality with a restrictive strategy seems rather hazardous as it is based on 2 studies only. With such a low number of included studies, it is difficult to interpret also the robustness of the results, considering that a trial sequential analysis has not been carried out [11].

In order to correct for all the above-mentioned concerns, we provide a forest plot including the 6 missed studies with an analysis performed according to the random-effects model. We used the longest follow-up mortality provided by the studies, rather than dispersing the

\section{karger@karger.com} www.karger.com/tmh

\section{(C) 2021 The Author(s)}

Published by S. Karger AG, Basel

This is an Open Access article licensed under the Creative Common Attribution-NonCommercial-4.0 International License (CC BY-NC) (http://www.karger.com/Services/OpenAccessLicense), applicable to the online version of the article only. Usage and distribution for commercial purposes requires written permission.
Correspondence to:

Filippo Sanfilippo, filipposanfi@yahoo.it 


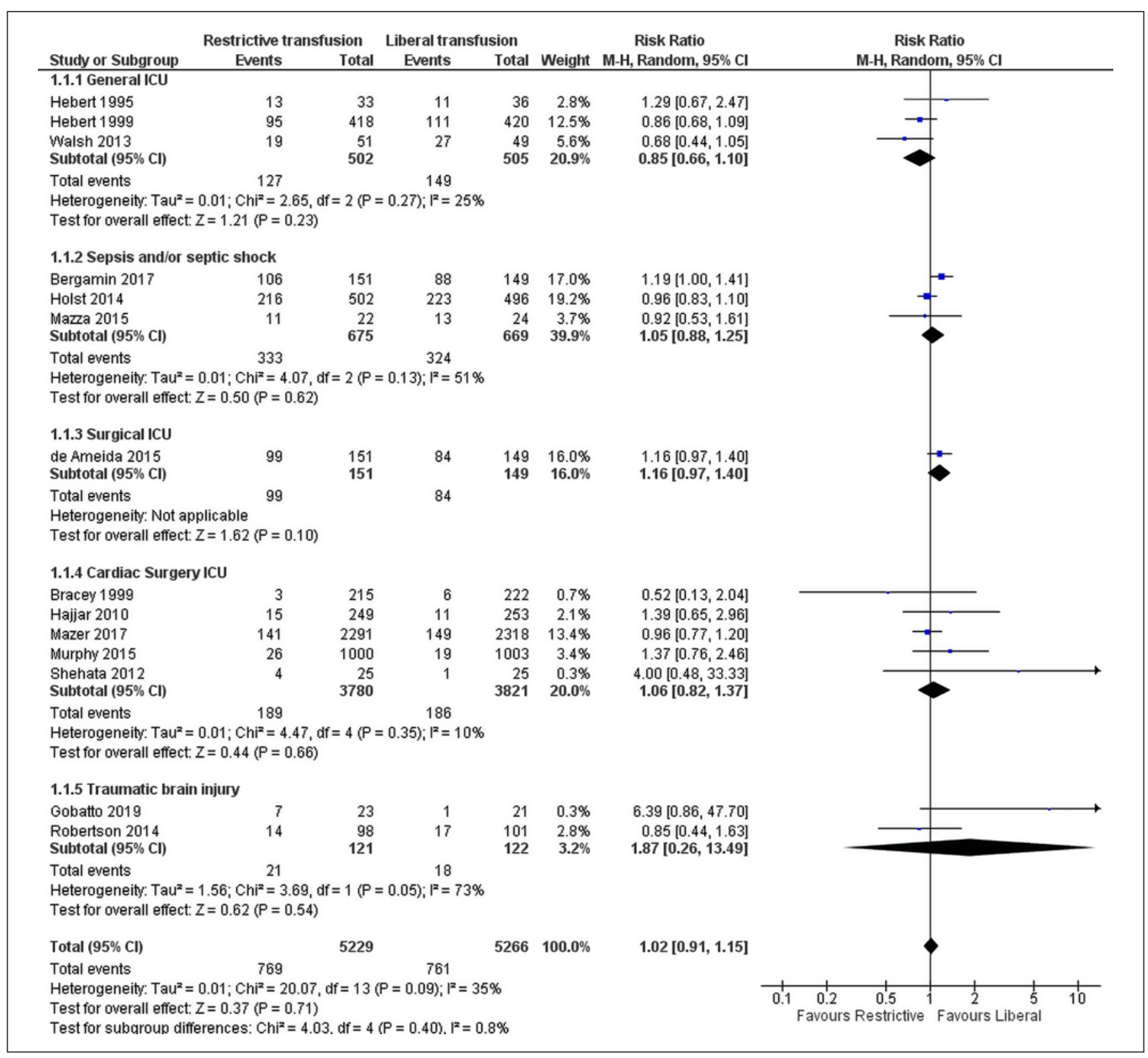

Fig. 1. Forest plot analysis on mortality at longest follow-up in critically ill patients randomized to a restrictive or liberal transfusion strategy. Analysis performed with random-effects model and Mantel-Haenszel (M-H). CI, confidence interval.

mortality outcome in multiple time points. Furthermore, we separated studies into subgroups according to the clinical setting. As shown in Figure 1, there were no differences in mortality according to the transfusion strategy: risk ratio 1.02 (95\% confidence interval $0.91-1.15 ; p=$ $0.71)$ with mild heterogeneity $\left(I^{2}=35 \%\right)$ and no subgroup differences $(p=0.40)$. Of note, our results remain unchanged if the analyses are limited to the studies strictly adhering to the original criteria (admission hemoglobin of $90 \mathrm{~g} / \mathrm{L}$ or less).
In light of the corrected approach with new studies included and with the use of the recommended effects model, our pooled results suggest that there is currently no difference in mortality in critically ill adult patients according to the transfusion strategy.

\section{Conflict of Interest Statement}

The authors have no conflicts of interest to declare. 


\section{Funding Sources}

There were no funding sources.

\section{Author Contributions}

All authors read and discussed the meta-analysis in a journal club. F.S., L.L.V., and P.M. conducted a search to find other relevant articles that were missed. F.S., L.L.V., and M.A. performed the meta-analysis. F.S. and L.L.V. wrote the draft of the manuscript. P.M. and M.A. revised the draft. All authors approved the final version.

\section{References}

1 Zhang W, Zheng Y, Yu K, Gu J. Liberal transfusion versus restrictive transfusion and outcomes in critically ill adults: a meta-analysis. Transfus Med Hemother. 2021;48(1):60-8.

2 Mazza BF, Freitas FG, Barros MM, Azevedo LC, Machado FR. Blood transfusions in septic shock: is $7.0 \mathrm{~g} / \mathrm{dL}$ really the appropriate threshold?. Rev Bras Ter Intensiva. 2015; 27(1):36-43.

3 Mazer CD, Whitlock RP, Fergusson DA, Hall J, Belley-Cote E, Connolly K, et al. Restrictive or liberal red-cell transfusion for cardiac surgery. N Engl J Med. 2017;377(22):2133-44.

4 Sanfilippo F, Tigano S, Palumbo GJ, Astuto $\mathrm{M}$, Murabito P. Importance of inclusion criteria in systematic reviews. Br J Anaesth. 2020; 125(5):e398-e399.
5 Bracey AW, Radovancevic R, Riggs SA, Houston S, Cozart H, Vaughn WK, et al. Lowering the hemoglobin threshold for transfusion in coronary artery bypass procedures: effect on patient outcome. Transfusion. 1999;39(10): 1070-7.

6 Shehata N, Burns LA, Nathan H, Hebert P, Hare GM, Fergusson D, et al. A randomized controlled pilot study of adherence to transfusion strategies in cardiac surgery. Transfusion. 2012;52(1):91-9.

7 Hajjar LA, Vincent JL, Galas FR, Nakamura RE, Silva CM, Santos MH, et al. Transfusion requirements after cardiac surgery: the TRACS randomized controlled trial. JAMA. 2010;304(14):1559-67.

8 Gobatto ALN, Link MA, Solla DJ, Bassi E, Tierno PF, Paiva W, et al. Transfusion requirements after head trauma: a randomized feasibility controlled trial. Crit Care. 2019; 23(1):89.
9 Robertson CS, Hannay HJ, Yamal JM, Gopinath S, Goodman JC, Tilley BC, et al. Effect of erythropoietin and transfusion threshold on neurological recovery after traumatic brain injury: a randomized clinical trial. JAMA. 2014;312(1):36-47.

10 Barili F, Parolari A, Kappetein PA, Freemantle N. Statistical Primer: heterogeneity, random- or fixed-effects model analyses?. Interact Cardiovasc Thorac Surg. 2018;27(3):31721.

11 Sanfilippo FLVL, Tigano S, Morgana A, La Rosa V, Astuto M. Trial sequential analysis: the evaluation of the robustness of meta-analyses findings and the need for further research. EuroMediterranean Biomed J. 2021; 16(25):104-7. 